\title{
Konservasi dengan rain water harvesting system sebagai solusi efektif bagi bangunan sekolah
}

\author{
S. Utami ${ }^{1,2 *}$, A. M. Nugroho ${ }^{1}$, Nikita ${ }^{1}$ \\ ${ }^{1}$ Jurusan Arsitektur, Fakultas Teknik, Universitas Brawijaya, Malang, Indonesia \\ ${ }^{2}$ Pusat Studi Lingkungan Hidup, LPPM Universitas Brawijaya, Malang, Indonesia
}

\begin{abstract}
Abstrak
Air merupakan kebutuhan utama makhluk hidup. Upaya konservasi air pada semua perencanaan dan perancangan bangunan dibutuhkan dalam menghadapi perubahan iklim yang kini terjadi. Konservasi air menjadi penting ketika air sebagai unsur utama dalam proses belajar mengajar siswa di sekolah kejuruan. Rain water harvesting system sebagai alternatif konservasi yang paling tradisional, mudah dan efektif. Tujuan utamanya adalah pemenuhan kebutuhan air bersih untuk operasional sekolah tersebut. Metode penelitian adalah deskriptif kualitatif terutama untuk menampilkan karakter fisik alam, tapak dan pola tata airnya. Hasil dan pembahasan berupa perencanaan rain water harvesting system pada kompleks bangunan sekolah dalam menangkap air hujan, termasuk elemen pelengkapnya. Selain itu, dilakukan pula proses daur ulang air limbah pada setiap bangunan untuk mengurangi efektivitas penggunaan air. Kesimpulannya rain water harvesting system sebagai upaya konservasi air yang paling sederhana, efektif dan mudah untuk direncanakan, dirancang dan dilaksanakan, terutama untuk bangunan sekolah kejuruan yang berbasis pengelolaan sumber daya air.
\end{abstract}

Kata kunci: konservasi, rain water harvesting system, bangunan sekolah

\begin{abstract}
.
Water is the main need for living things. Even though water can be renewed, the impact of climate change requires water conservation efforts in building planning and design. Water conservation becomes important when water is the main element in the learning process of students in vocational schools. Rain water harvesting system is the most traditional, easy and effective conservation alternative. The main objective was to meet the needs of clean water for the operation of the school. The research method was qualitative descriptive mainly to display the physical character of nature, the site and the pattern of the water system. The results and discussion in the form of planning the rain water harvesting system in the school building complex in capturing rainwater, including its complementary elements. In addition, recycling of waste water in each building was also carried out to reduce the effectiveness of water use. The conclusion was rain water harvesting system as the simplest, effective and easy water conservation effort to be planned, designed and implemented, especially for building vocational schools based on water resources management.
\end{abstract}

Keywords: conservation, rain water harvesting system, building of schools

\section{PENDAHULUAN}

Indonesia memiliki dua iklim yakni musim kemarau dan musim hujan. Siklus perubahan musim ini telah banyak mengalami pergeseran waktu dan besaran. Secara umum, bulan-bulan musim penghujan dan kemarau telah berubah. Ketika di wilayah Indonesia seharusnya musim kemarau, namun terjadi musim penghujan dengan hujan yang lebat, sementara pada saat musim penghujan telah terjadi hal yang sebaliknya. Dampak perubahan iklim telah dirasakan dan mengubah siklus bulan dan tahunan pada suatu wilayah tertentu. Worm and Hattum (2006) menyatakan bahwa mayoritas penduduk di dunia sulit untuk mendapatkan akses terhadap air bersih. Sementara target LEAD (2016) dalam Sustainable Development Goals (goal 6) adalah kemudahan akses air minum, sanitasi serta pemanfaatan, pengelolaan dan pelestarian sumber

\footnotetext{
${ }^{*}$ Korespondensi Penulis

Email : sriutamiazis@gmail.com
} 
daya air, termasuk ketersediaan air untuk proses pendidikan di sekolah. Perencanaan pengelolaan sumber daya air menjadi penting untuk dilakukan sesuai PerMenDikNas Nomor 40 Tahun 2008 tentang Standar Sarana dan Prasarana Sekolah Menengah Kejuruan. Sistem penampung air hujan merupakan salah satu alternatif pemenuhan kebutuhan air bersih (Nadia dan Mardyanto 2016), terutama bagi sekolah yang berbasis manajemen pengelolaan sumber daya air. Konservasi air di sekolah sebagai suatu kebutuhan untuk mendapatkan air bersih sebagai bagian dari proses belajar siswa.

Konservasi air merupakan manajemen penggunaan dan pengolahan air di areal tapak dan bangunan yang dilakukan secara sistematis, efisien dan tepat guna (Kwok and Grondzik 2004; Kwok and Grondzik 2007). Prinsip konservasi air ini bisa dilakukan dari skala bangunan (semua bangunan termasuk bangunan sekolah) hingga skala tapak. Konservasi air di skala bangunan dilakukan dengan mempertimbangkan standar kebutuhan air, penggunaan fitur air, penggunaan sistem daur ulang air limbah (grey water) dan pemanfaatan rain water harvesting system atau sistem pemanenan air hujan. Prinsip daur ulang ini diharapkan dapat mengurangi volume air kotor yang berasal dari septic tank untuk bisa digunakan kembali (re-use), sehingga bangunan tidak mengganggu kualitas lingkungan sekitarnya. Konservasi air pada skala tapak dilakukan dengan menjaga keseimbangan jumlah air tanah dengan cara memperluas area penyerapan air, penggunaan tipe perkerasan memudahkan penyerapan air ke dalam tanah (pervious surfaces), pembuatan lubang biopori dan efisiensi penggunaan air dari lanskap untuk penyiraman tanaman.

Metode konservasi air dengan pemanfaatan rain water harvesting system ini merupakan metode paling tradisional dan berkelanjutan, karena mudah digunakan untuk tujuan konservasi (Rahman et al. 2014). Pada sistem ini air hujan ditampung, lalu diolah menjadi air bersih melalui tahap filtrasi. Pengolahan dilakukan karena air hujan yang ditampung oleh permukaan penangkap sama sekali tidak layak minum.

Menurut Asdak (2007), sistem pemanenan air hujan ini dibedakan menjadi dua yakni atap bangunan (roof catchment) sebagai penampung air hujan dan permukaan tanah (ground catchment) sebagai penampung air hujan. Sistem roof catchment berupa penyaluran dan pengumpulan air hujan dari atap rumah atau bangunan besar dan di atas permukaan tanah (surface run off). Volume air hujan yang terkumpul sangat ditentukan oleh kemiringan dan topografi bidang tangkapan, serta kemampuan lapisan tanah atas dalam menahan air (Li et al. 2003). Oleh karena itu, Sistem Pemanfaatan Air Hujan (SPAH) berupa penampungan air hujan (PAH) dan pengolahan air hujan yang selalu diperlengkapi oleh penyalur air (talang), pasir sebagai penyaring, bak sebagai penampung dan sumur untuk meresapkan (KELAIR 2016). 
Sistem rain water harvesting sudah digunakan sejak zaman dahulu dan hal ini dibuktikan dari atap bagian belakang zaman Romawi Kuno. Rumah orang Romawi di daerah perkotaan pada umumnya desainnya rata. Hal ini digunakan untuk menerima air hujan yang turun, dengan pengertian bahwa air hujan tersebut bisa untuk kebutuhan air minum dan rumah tangga (Southface Energy Institute 2002). Hasil studi Nurrizqi et al. (2016) menunjukkan bahwa terjadi pengurangan dampak bencana banjir di DAS Penguluran, Kecamatan Sumbermanjing Wetan, Kabupaten Malang melalui penerapan rain water harvesting system.

Berdasarkan hal tersebut, muncul gagasan perlunya analisis terhadap upaya konservasi air melalui sistem rain water harvesting pada semua bangunan sekolah sebagai bagian dari proses pendidikan, khususnya SMK Perikanan di Kabupaten Malang. Analisis neraca air sangat diperlukan terkait konservasi air, terutama bagi sekolah kejuruan perikanan yang berbasis pengelolaan sumber daya air. Hal ini sejalan pula dengan salah satu program yang dikembangkan di Kabupaten Malang yaitu mewujudkan kawasan minapolitan (KepBup Malang Nomor 180 Tahun 2008 tentang Penetapan Lokasi Pengembangan Kawasan Minapolitan) dengan komoditas utama ikan nila.

\section{METODOLOGI}

\subsection{Lokasi kajian dan waktu penelitian}

Lokasi penelitian di Desa Wajak, Kecamatan Wajak, Kabupaten Malang. Lokasi ini berada di kaki Gunung Semeru bagian barat, terletak pada koordinat $8^{\circ} 21^{\prime} 45^{\prime \prime}$ LS dan $112^{\circ} 37^{\prime} 32^{\prime \prime}-122^{\circ} 54^{\prime} 56^{\prime \prime}$ BT, dengan luas areal sekitar $9456 \mathrm{Ha}$. Lokasi tapak di Jalan Panglima Sudirman, yang menjadi jalan utama Kecamatan Wajak, jauhnya sekitar $1 \mathrm{~km}$ dari Kantor Kecamatan Wajak dan sekitar $35 \mathrm{~km}$ dari Kota Malang. Suhu udara di lokasi tapak berkisar $20-32^{\circ} \mathrm{C}$ dengan curah hujan mencapai 1297-1925 mm.

\subsection{Prosedur analisis data}

Penelitian berawal dari pemikiran evaluasi terhadap target SDGs (LEAD 2016) yaitu pelestarian dan pemanfaatan sumber daya air. Pemikiran ini dilatarbelakangi oleh tingginya kebutuhan air untuk pemenuhan proses belajar mengajar pada bangunan pendidikan yang berbasis pada pengelolaan sumber daya air, khususnya SMK Perikanan (hasil studi pendahuluan dengan obyek yang sama atau hampir sama). Sementara, kebutuhan air bersih untuk siswa sekolah umum adalah 15-30 liter/orang/hari.

Metode yang digunakan adalah deskriptif kualitatif dengan memaparkan beberapa fakta lapang dari hasil studi mengenai aktivitas pemanfaatan sumber daya air. Proses penelitian terbagi menjadi 2 (dua) tahap. Tahap pertama adalah 
pengumpulan data primer dan sekunder. Data primer diambil dari observasi langsung di lokasi penelitian melalui pencatatan aspek lingkungan (topografi/kemiringan, curah hujan, iklim) sebagai bahan analisis. Pengumpulan data melalui foto eksisting untuk memahami karakter tapak (aksesibilitas, jaringan utilitas) dan kebutuhan sumber daya air untuk mendukung aktivitas pendidikan. Selanjutnya, dilakukan wawancara terhadap pihak terkait (pengelola, siswa dan masyarakat sekitar).

Data sekunder didapatkan dari instansi terkait dan referensi (artikel, jurnal ilmiah, skripsi, tesis, buku, dsb.) yang berhubungan dengan penerapan tata air pada lingkungan dan bangunan. Data curah hujan sebagai data sekunder dibutuhkan untuk menghitung debit, kebutuhan tampungan air, serta pola tata aliran air dalam site dan bangunan. Bila rata-rata curah hujan di sekitar site sangat tinggi, maka sangat disayangkan apabila air hujan tidak dimanfaatkan secara maksimal. Data sekunder juga dikumpulkan dari beberapa sumber, antara lain:

- RTRW Kabupaten Malang.

- Deskripsi dan teori mengenai fasilitas dan aktivitas sekolah kejuruan perikanan.

- Penerapan sumber daya air pada sistem bangunan.

- Standar fungsional bangunan sekolah.

Tahap Kedua adalah analisis kebutuhan air dengan metode prakiraan laju aliran puncak (debit banjir atau debit rencana) dengan Metode Rasional USSCS (1973). Asumsi dalam metode ini adalah curah hujan yang terjadi memiliki intensitas seragam dan merata pada semua daerah pengaliran, selama setidaknya sama dengan waktu konsentrasi (tc). Formula matematisnya adalah:

$$
\mathrm{Q}=0,278 . \text {.I.I.A }
$$

Keterangan :

$\mathrm{Q} \quad=\operatorname{Debit}\left(\mathrm{m}^{3} /\right.$ detik $)$

$0,278=$ Konstanta, dipergunakan jika satuan luas daerah menggunakan $\mathrm{km}^{2}$

$\mathrm{C}=$ Koefisien aliran

I = Intensitas curah hujan selama waktu konsentrasi (mm/jam)

A = Luas daerah aliran $\left(\mathrm{km}^{2}\right)$

Rumus pragmatik tersebut digunakan sebagai bahan analisis kebutuhan air dan besarann sumur PAH di dalam site. Selanjutnya dilakukan sintesis untuk mendapatkan perencanaan dan perancangan pada skala tapak dan bangunan .

\section{HASIL DAN PEMBAHASAN}

Tapak memiliki luas sebesar 2,65 ha dengan ketinggian wilayah $525 \mathrm{mdpl}$ dengan ketinggian kontur $1,5 \mathrm{~m}$ dan kemiringan $<15^{0}$. Orientasi tapak menghadap ke arah utara, sehingga bentuk tapak membujur dari arah barat 
menuju timur. Kontur tertinggi berada di sisi barat tapak dan terendah berada di sisi timur, seperti Gambar 1 dan 2.

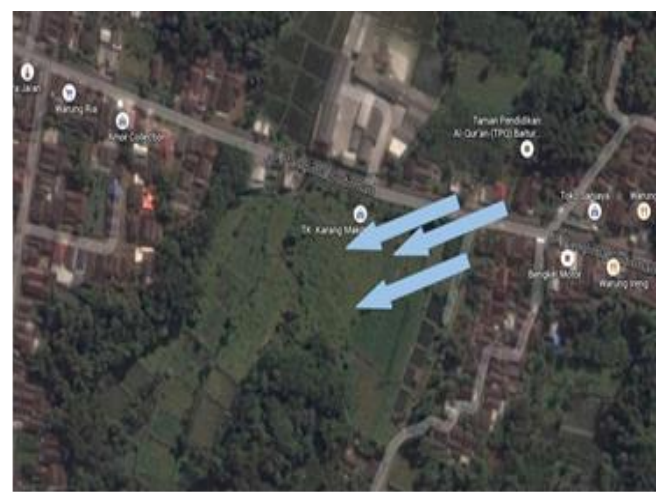

Gambar 1. Lokasi tapak.

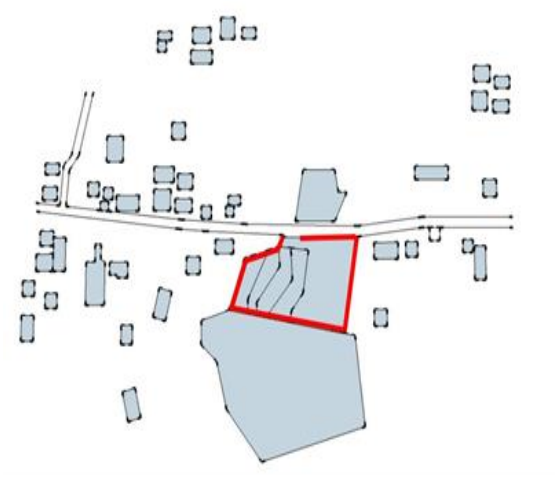

Gambar 2. Tapak dan lingkungan sekitar.

Setelah dilakukan analisis terhadap curah hujan, kontur tapak dan arah aliran air, maka diperoleh pembagian zonasi dan perencanaan, seperti pada Gambar 3 dan 4.

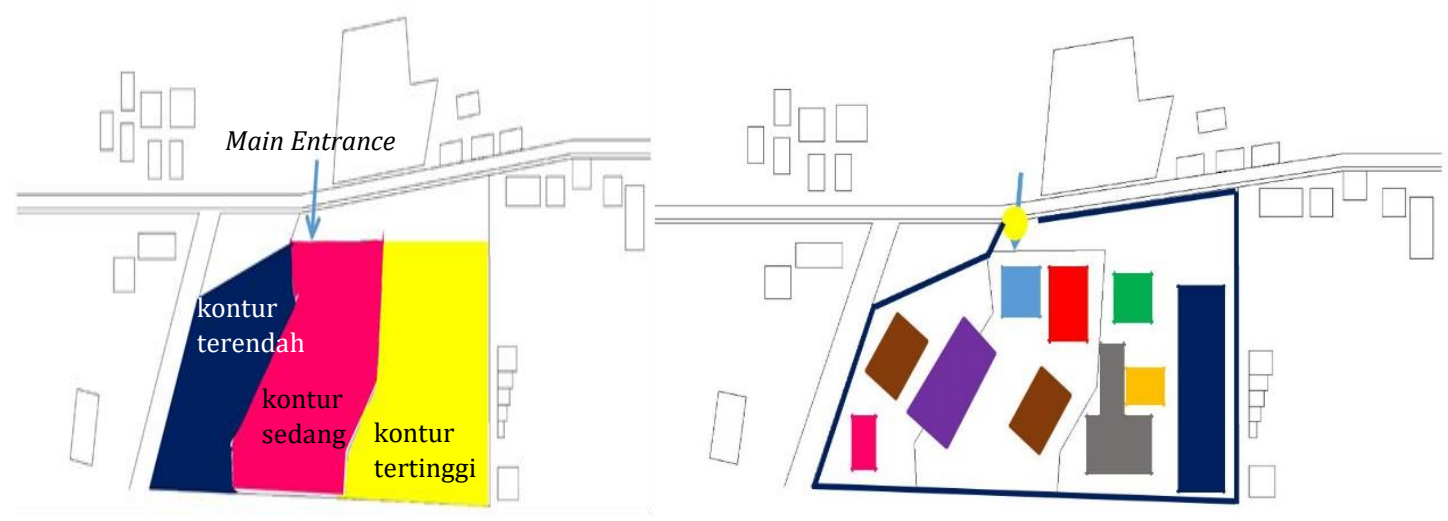

Gambar 3. Pembagian zonasi.

Gambar 4. Site plan.

\subsection{Hasil analisis kebutuhan air}

Konservasi air pada bangunan sekolah ini mengikuti prinsip efisiensi. Penerapan rain water harvesting system adalah dengan menangkap air hujan pada bagian atap, selanjutnya dialirkan dan ditampung pada sumur penampungan air hujan (PAH) yang kemudian dapat digunakan sebagai pemenuhan kebutuhan air bersih utama, seperti yang tersaji pada Gambar 5. 


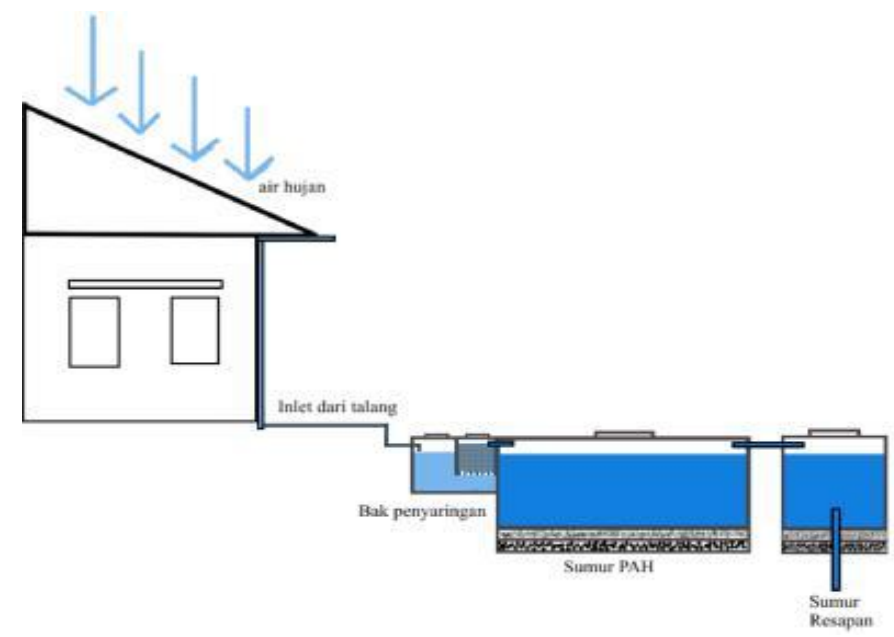

Gambar 5. Skema rain water harvesting system.

Besaran PAH bangunan menyesuaikan keperluan air bersih dalam 1 bulan pada 1 bangunan, sedangkan besaran sumur PAH komunal menyesuaikan keperluan air bersih dalam 6 bulan pada seluruh bangunan di lokasi site. Rumus yang digunakan adalah (Goldman et al. 1986):

$$
\mathrm{Q} \text { hujan-maks }=(0,278) \cdot \text { C.I.A }
$$

Keterangan :

Q hujan-maks = Debit maksimum $\left(\mathrm{m}^{3} /\right.$ detik $)$

C

I $\quad=$ Curah hujan $\left(\mathrm{mm} / \mathrm{m}^{2} / \mathrm{jam}\right)$

A

$$
\begin{aligned}
& =\text { Koefisien aliran } \\
& =\text { Curah hujan }\left(\mathrm{mm} / \mathrm{m}^{2} / \mathrm{jam}\right) \\
& =\text { Luas area yang dihitung }\left(\mathrm{km}^{2}\right)
\end{aligned}
$$

Besaran C diperoleh dari tabel koefisien aliran dalam buku Struktur Bangunan Tinggi. Nilai koefisien aliran air pada atap sebesar 0,70-0,95. Besaran I diperoleh dari analisis data 5 tahun terakhir curah hujan. Perhitungannya sebagai berikut:

$$
\begin{aligned}
\mathrm{I} & =\text { Total curah hujan : total hari hujan : estimasi waktu turun hujan } \\
& =11417: 664: 6=2,85 \mathrm{~mm} / \mathrm{m}^{2} / \mathrm{jam}
\end{aligned}
$$

Besaran A diperoleh dari penjumlahan luasan seluruh atap massa bangunan di dalam site yakni sebesar $5225 \mathrm{~m}^{2}=0,05 \mathrm{~km}^{2}$. Debit curah hujan pada site adalah:

$$
\begin{aligned}
\mathrm{Q} & =(0,278) \cdot C \cdot I \cdot A \\
& =(0,278) \cdot 0,8 \cdot 2,85 \cdot 0,05 \\
& =0,031 \mathrm{~m}^{3} / \text { detik }
\end{aligned}
$$

Lamanya hujan turun diperkirakan 30 menit, maka total jumlah hujan yang turun adalah:

Debit air hujan $\times$ lama hujan turun $=31 \times(60 \times 30)=31 \times 180=5580 \ell$, seperti pada Tabel 1 dan Gambar 6. 
Tabel 1. Kebutuhan air di musim penghujan.

\begin{tabular}{|c|c|c|c|}
\hline \multirow{2}{*}{ No } & \multirow{2}{*}{ Massa Bangunan } & \multicolumn{2}{|c|}{ Musim Hujan } \\
\hline & & Masuk & Keluar \\
\hline 1 & Massa Bangunan Administrasi & $5580 \ell /$ hari & $340 \ell /$ hari \\
\hline 2 & Massa Bangunan Pembelajaran Umum & $5580 \ell /$ hari & $1940 \ell /$ hari \\
\hline 3 & Jurusan Teknika & $5580 \ell /$ hari & $365 \ell /$ hari \\
\hline 4 & Jurusan Pengolahan & $5580 \ell /$ hari & $365 \ell /$ hari \\
\hline 5 & Jurusan Budidaya & $5580 \ell /$ hari & $1005 \ell /$ hari \\
\hline
\end{tabular}

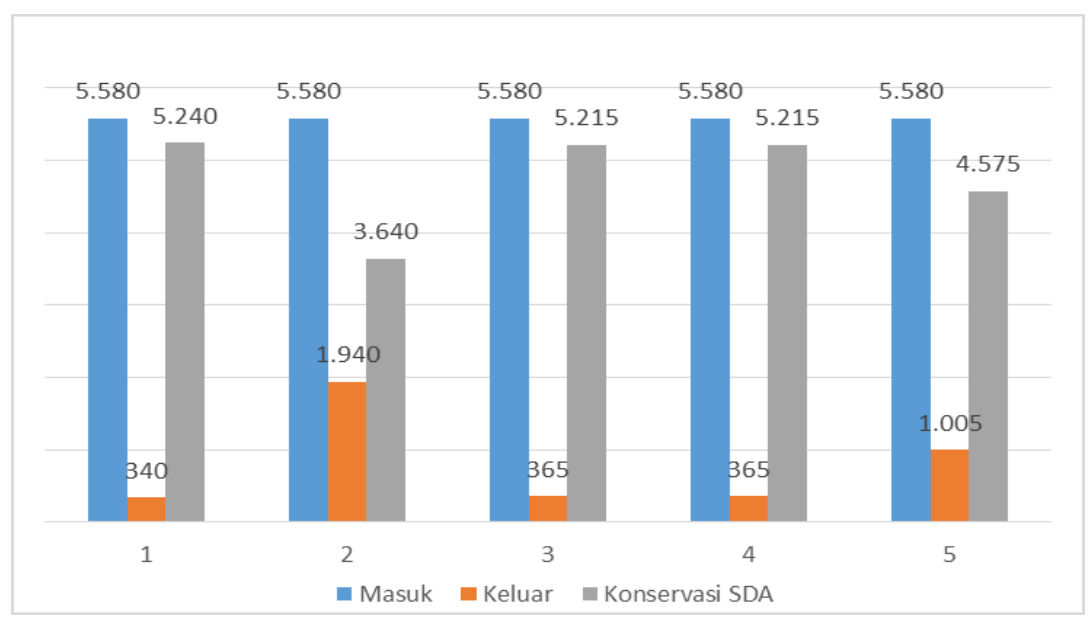

Gambar 6. Konservasi air (cash-flow air) di musim penghujan.

Berdasarkan Gambar 6, pada musim penghujan terjadi peningkatan jumlah air yang tersimpan, sehingga jumlah volume air tersebut cukup aman untuk ketersediaan operasional sekolah 6 (enam) bulan mendatang. Jumlah air yang bisa dikonservasi pada massa bangunan 1 (5240 $\ell$ /hari), massa bangunan 2 (3640 $\ell$ /hari), massa bangunan 3 (5215 $\ell$ /hari), massa bangunan 4 (5215 $\ell$ /hari) dan massa bangunan 5 (4575 $\ell$ /hari). Khusus bangunan dengan fungsi pembelajaran umum harus mempunyai treatment perencanaan khusus agar dapat meningkatkan jumlah volume simpanan airnya agar lebih dari 3640 $\ell$ /hari, seperti pada Tabel 2 dan Gambar 7.

Tabel 2. Perhitungan kebutuhan air di musim kemarau.

\begin{tabular}{llcc}
\hline \multirow{2}{*}{ No } & \multicolumn{1}{c}{ Massa Bangunan } & \multicolumn{2}{c}{ Musim Kemarau } \\
\cline { 3 - 4 } & & $2160 \ell /$ hari & $340 \ell /$ hari \\
\hline 1 & Massa Bangunan Administrasi & $2160 \ell /$ hari & $1940 \ell /$ hari \\
2 & Massa Bangunan Pembelajaran Umum & $2160 \ell /$ hari & $365 \ell /$ hari \\
3 & Jurusan Teknika & $2160 \ell /$ hari & $365 \ell /$ hari \\
4 & Jurusan Pengolahan & $2160 \ell /$ hari & $1005 \ell /$ hari \\
5 & Jurusan Budidaya & & \\
\hline
\end{tabular}




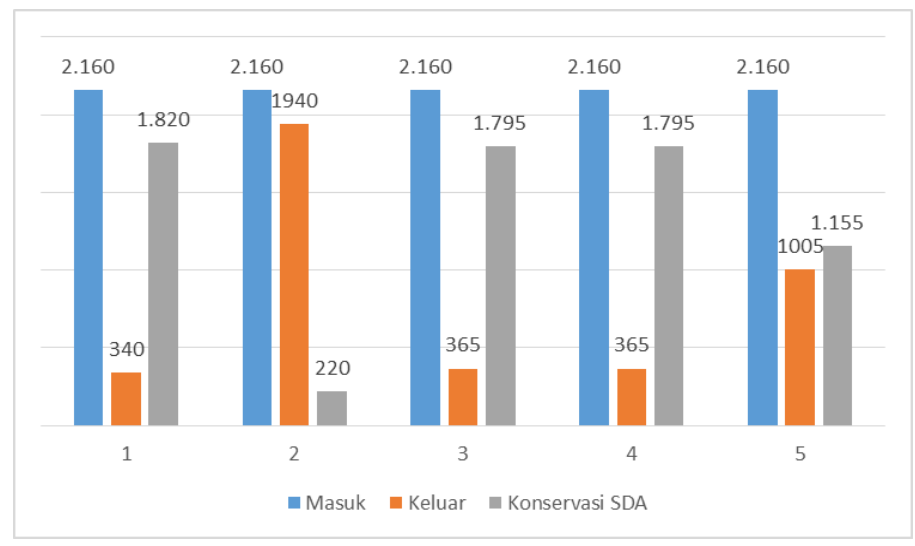

Gambar 7. Konservasi air (cash-flow air) di musim kemarau.

Berdasarkan Gambar 7, pada musim kemarau terjadi peningkatan kebutuhan air terutama pada massa bangunan 2 (Massa Bangunan Pembelajaran Umum), sehingga penyimpanan air hanya $220 \ell$ /hari. Khusus pada massa bangunan 1, volume air yang disimpan mencapai $1820 \ell /$ hari. Massa Bangunan 3, sebesar $1795 \ell$ /hari, massa bangunan 4 sebesar $1795 \ell$ /hari dan massa bangunan 5 sebesar $1155 \ell$ /hari. Namun kondisi ini masih dipenuhi oleh penyimpanan air dari bangunan 1 (Massa Bangunan Administrasi) karena operasional PAH komunal pada site. PAH tersebut dapat berbentuk balok, yang konstruksinya berupa beton, dilengkapi penyalur berupa pipa HDPE, serta ukuran PAH disesuaikan terhadap kebutuhan air di setiap massa bangunan.

Hasil analisis curah hujan dan kebutuhan air pada setiap bangunan akan saling terkoneksi bila setiap massa bangunan dilengkapi sumur PAH. Sumur PAH ini bertujuan memudahkan pendistribusian air bersih dari setiap massa bangunan. Alur distribusi air bersih ditunjukkan oleh Gambar 8.

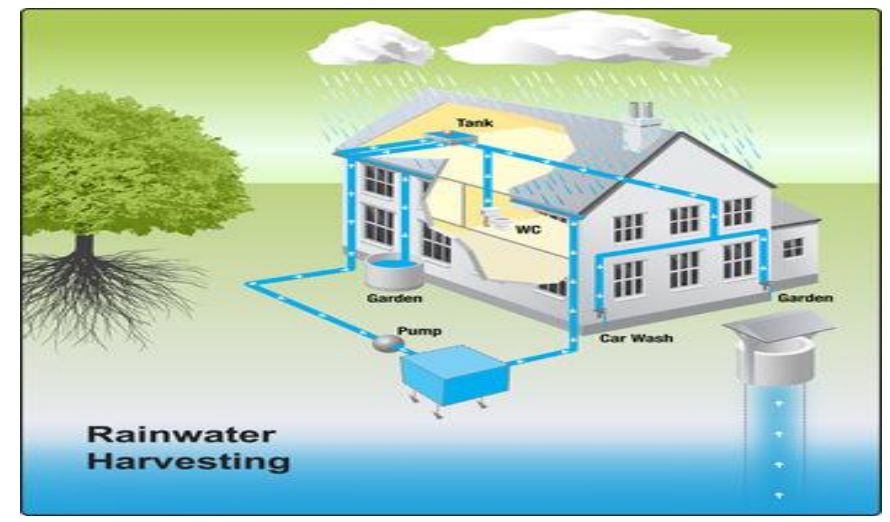

Gambar 8. Distribusi air bersih dari atap bangunan ke sumur PAH. sumber: KELAIR (2016) 
Alur sistem pemanfaatan air hujan (SPAH) dimulai dari penyaluran air hujan yang jatuh pada atap bangunan melalui pipa menuju bak penampung awal yang berisi saringan pasir-kerikil. Selanjutnya, air disalurkan ke bak tampungan yang didesain memiliki volume antara $10-12 \mathrm{~m}^{3}$. Kelebihan air akan diresapkan ke dalam tanah. Selengkapnya mengenai SPAH ini disajikan pada Gambar 9.

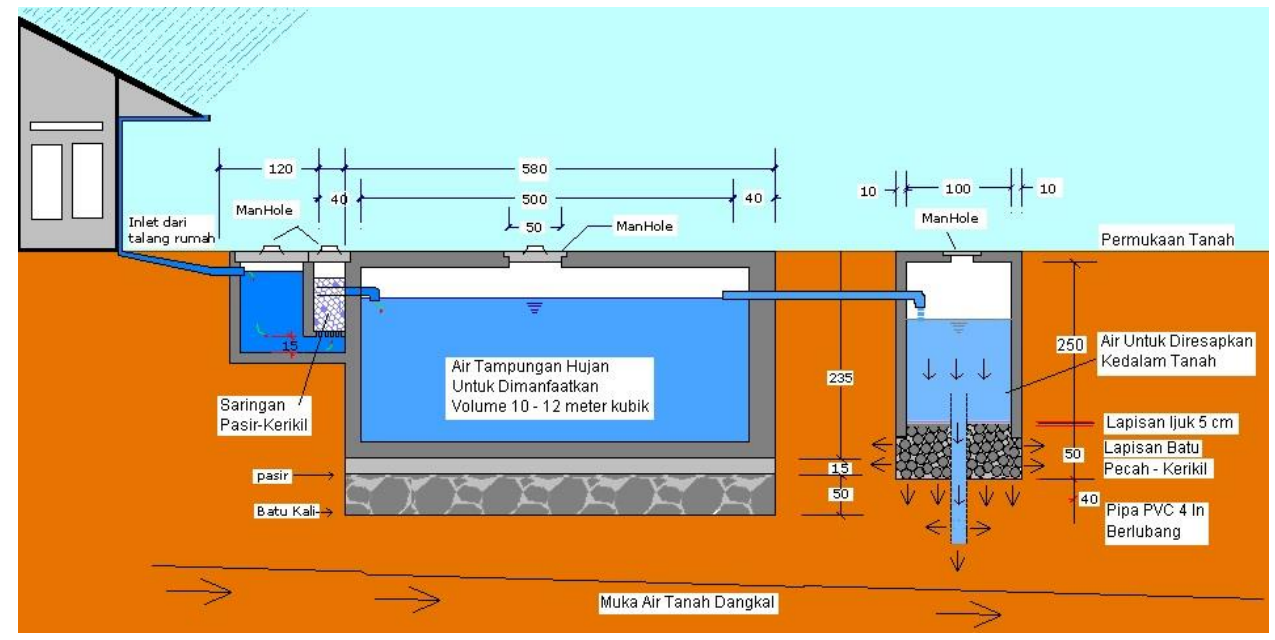

Gambar 9. Sistem pemanfaatan air hujan (SPAH) dan sumur resapan di dalam tapak. sumber: KELAIR (2016)

Sesuai perencanaan, pada musim kemarau, air dari sumur PAH komunal akan digunakan sebagai pemenuhan kebutuhan air bersih pada bangunan, dengan cara dialirkan menuju sumur PAH di setiap massa bangunan. Sebagai alternatif, manakala kebutuhan air bersih tidak dapat dipenuhi oleh air sumur PAH komunal, maka akan diperlukan sumur bor. Proses tersebut digambarkan pada Gambar 10.



Gambar 10. Posisi PAH bangunan. 
Air kotor dari septic tank dan kolam praktikum dialirkan ke Instalasi Pengolahan Air Limbah (IPAL) yang diolah dengan sistem aerob-anaerob, lalu dimanfaatkan kembali bagi penyiraman tanaman dan toilet. Proses tersebut seperti digambarkan pada Gambar 11.

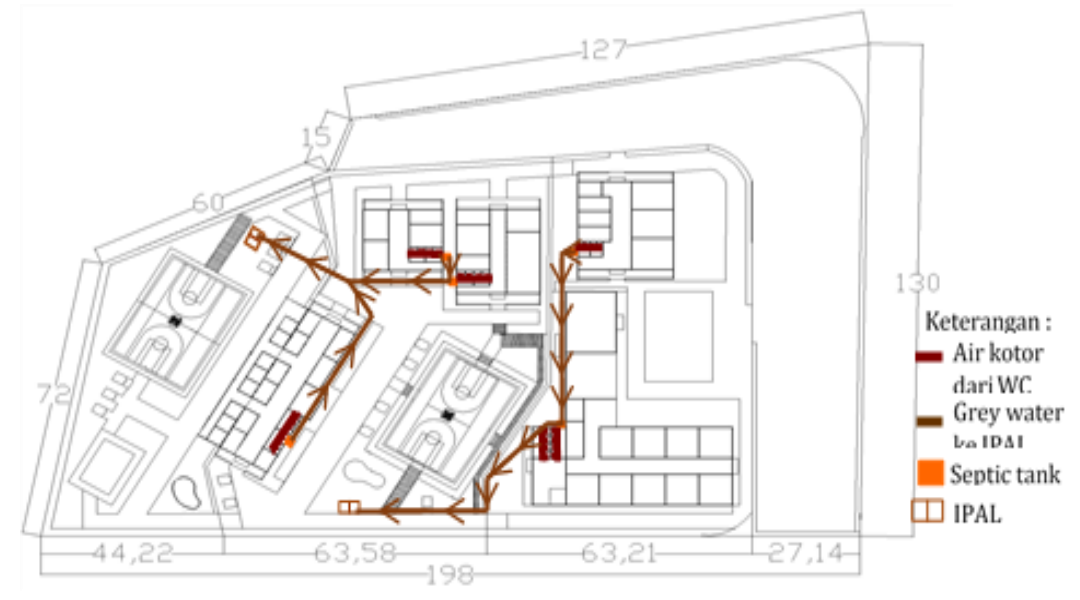

Gambar 11. Aliran air kotor dan IPAL.

Kolam praktikum berada di dalam massa bangunan Jurusan Budidaya Perikanan Air Tawar yang berlokasi di daerah berkontur guna kemudahan dalam proses irigasi kolam praktikum. Kolam yang berukuran lebih kecil (kolam induk jantan, induk betina dan pemijahan) diposisikan di daerah yang lebih tinggi, sedangkan kolam yang lebih besar (pendederan dan produksi) diposisikan di daerah yang lebih rendah.

Sistem filtrasi pada kolam praktikum akan efektif dengan penerapan filtrasi sederhana (tradisional) yang telah ditetapkan oleh Kementerian PUPR (2016). Filtrasi ini juga digunakan untuk penjernihan air sungai, air banjir dan air danau agar layak minum. Filtrasinya terdiri dari kerikil untuk penyaringan kotoran kasar, ijuk sebagai penyaringan kotoran halus dan pasir halus untuk mengendapkan kotoran berukuran halus yang tidak tersaring oleh ijuk. Arang berfungsi untuk menghilangkan bau. Kerikil berfungsi untuk mengalirkan air ke bagian bawah melalui celah-celahnya. Batu besar memiliki dengan kerikil, namun memiliki celah yang lebih besar. Perawatan rutin dilakukan secara berkala setiap 2-3 bulan, disertai dengan penggantian media ijuk setiap 6 bulan.

Hasil analisis, menunjukkan bahwa konservasi air dengan SPAH bisa mengurangi jumlah limpasan air dan mengurangi eksploitasi sumber daya air sekitarnya hingga mencapai 1500 liter/hari. Konsep ini bisa pula dilakukan untuk semua massa bangunan, terutama massa bangunan sekolah yang membutuhkan ketersediaan air yang cukup sebagai penunjang utama proses pendidikan. 


\subsection{Rekomendasi dan arahan desain}

Hasil analisis menunjukkan bahwa atap massa bangunan dengan tritisan lebar akan dapat menampung air hujan secara maksimal (SNI 03-706-2005). Penutup material keramik pada atap massa bangunan akan membantu mempercepat aliran air untuk menuju sumur PAH (Chang et al. 2004). Namun, Smotherman (2013) menyatakan untuk desain massa bangunan dengan rain water harvesting system, material atap perlu diperhatikan. Pertimbangan pemilihan material atap berdasarkan pada kemudahan mengalirkan air serta sifat material atap yang cenderung menyerap air atau tidak. Kecepatan aliran air hujan berbanding lurus dengan jumlah air yang akan ditampung. Material atap dengan tekstur kasar cenderung mengalirkan air lebih lambat daripada material atap bertekstur licin. Semakin cepat air hujan yang dialirkan, maka semakin banyak pula air hujan yang akan ditampung. Sumur PAH, filter dan arah aliran air hujan, seperti pada Gambar 12.

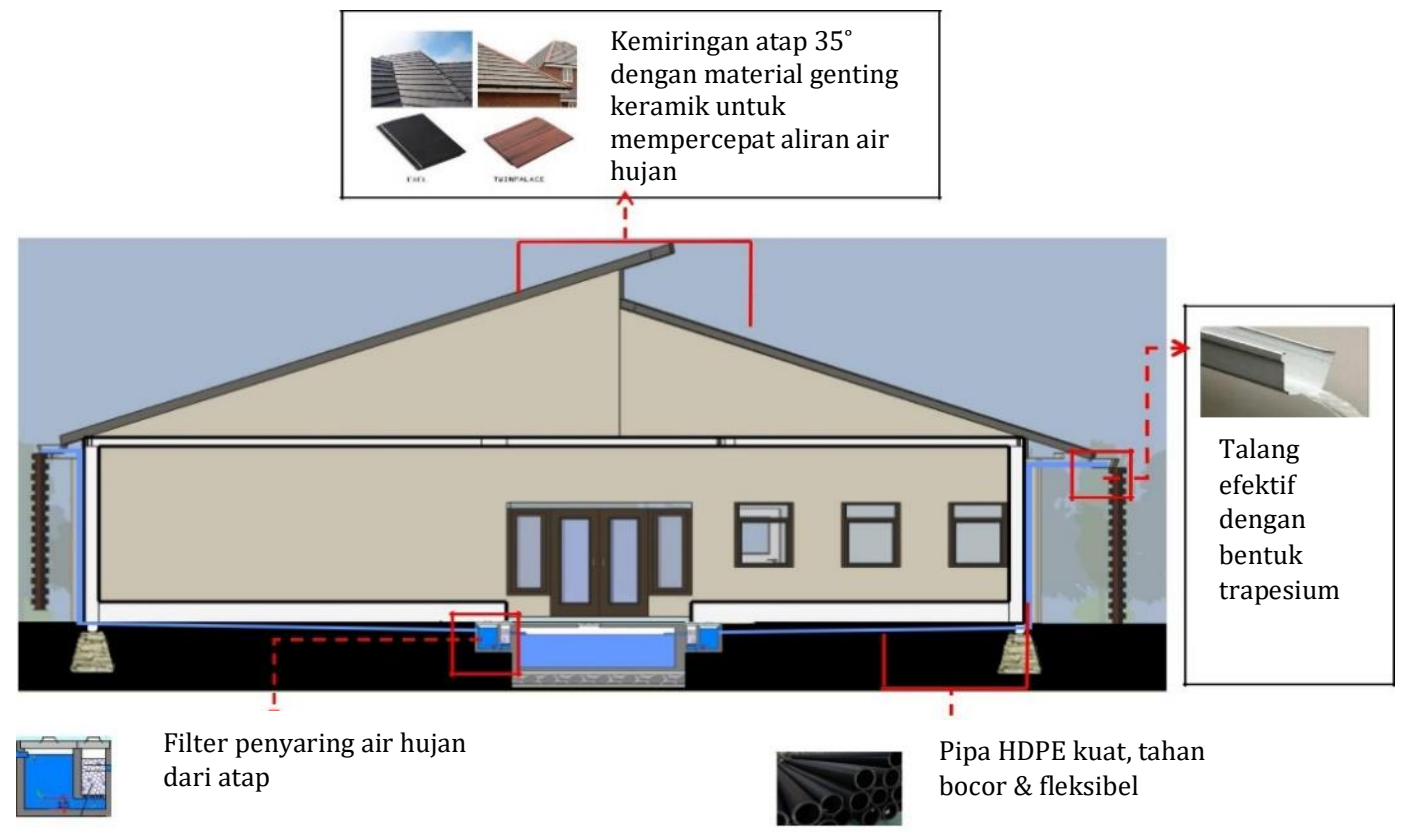

Gambar 12. Kemiringan dan material atap untuk konservasi air.

Pemanfaatan secondary skin sangat disarankan, karena bermanfaat guna menutupi sejumlah talang pada dinding massa bangunan, agar tetap terlihat rapi dan serasi, seperti ditunjukkan pada Gambar 13. 


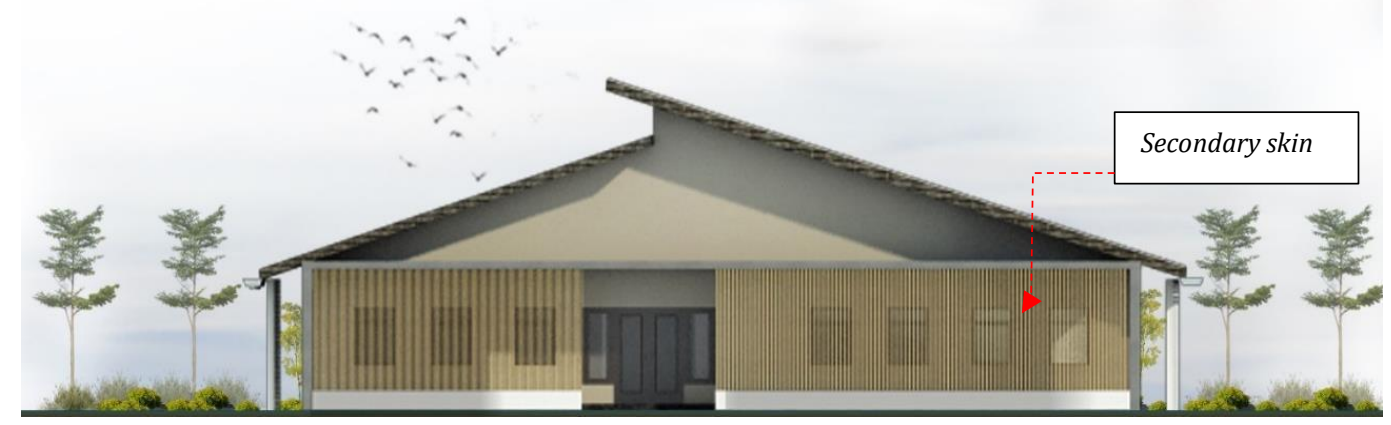

Gambar 13. Penggunaan secondary skin pada dinding massa bangunan.

Perencanaan ruang luar terutama area pedestrian way menggunakan grass block, sehingga dapat membantu mengurangi banjir pada area pejalan kaki guna membantu memaksimalkan proses penampungan air hujan ke dalam tanah. Pada bagian atapnya menggunakan pergola dengan kisi-kisi berlubang untuk meningkatkan peresapan air hujan, seperti Gambar 14.



Gambar 14. Kisi-kita pada atap pergola sebagai peneduh dan mempermudah resapan air hujan ke dalam tanah.

Berdasarkan hasil analisis dan sintesa, diketahui bahwa:

- Pada konsep rain water harvesting system, atap bangunan berfungsi sebagai elemen utama dalam menangkap air hujan. Bentuk atap dan material bangunan dapat dibentuk dan dipilih sesuai tuntutan karakter tampungan air. 
- Sumur PAH yang menyimpan air dapat digunakan sebagai sumber air bersih utama pada bangunan, setelah melalui sistem filtrasi yang menyaring kotoran serta zat-zat yang terkandung dalam air (Desain Pemanfaatan Air Hujan dan Sumur Resapan (KELAIR 2016)).

- Aplikasi IPAL yang menggunakan sistem biofilter aerob-anaerob disarankan bagi pengolahan grey water dari septic tank dan air limbah kolam praktikum, agar air bisa dimanfaatkan kembali guna penyiraman tanaman dan toilet.

- Sumur bor dapat digunakan sebagai pilihan, agar bangunan tidak perlu memanfaatkan PDAM sebagai sumber air bersih.

\section{KESIMPULAN DAN SARAN}

Konservasi melalui rain water harvesting system sangat dibutuhkan bagi bangunan pendidikan yang mengandalkan pengelolaan sumber daya air, seperti sekolah kejuruan perikanan yang berbasis pengelolaan sumber daya air. Prinsip konservasi model ini akan tidak mengganggu kestabilan dan ketersediaan air di lingkungan sekitarnya. Konsep ini sangat mudah dan efektif untuk direncanakan pada semua massa bangunan dimulai dari skala tapak hingga massa bangunan sebagai bentuk adaptasi dan mitigasi terhadap perubahan iklim.

\section{DAFTAR PUSTAKA}

Asdak C. 2007. Hidrologi dan pengelolaan daerah aliran sungai. Gadjah Mada University Press. Yogyakarta.

Chang M, McBroom MW and Beasley RS. 2004. Roofing as a source of nonpoint water pollution. Journal of Environmental Management 73:307-315.

Goldman SJ, Jackson K and Bursztynsky TA. 1986. Erosion and sediment control handbook. McGraw-Hill. New York.

[KELAIR] Kelompok Teknologi Pengelolaan Air Bersih dan Limbah Cair, Badan Pengkajian dan Penerapan Teknologi. 2016. Sistem pemanfaatan air hujan (SPAH) dan pengolahan air siap minum (ARSINUM) [internet]. Tersedia di: http://www.kelair.bppt.go.id/Sitpa/Artikel/Spah/spah.html.

[Kementerian PUPR] Kementerian Pekerjaan Umum dan Perumahan Rakyat. 2016. Panduan pendampingan sistem penyediaan air minum (SPAM) perpipaan berbasis masyarakat. Direktorat Jenderal Cipta Karya, Kementerian PUPR. Jakarta.

KepBup (Keputusan Bupati) Malang Nomor 180 Tahun 2008 tentang penetapan lokasi pengembangan kawasan minapolitan.

Kwok AG and Grondzik WT. 2004. The green studio handbook: environmental strategies for schematic design. Architectural Press. Oxford.

Kwok A and Grondzik W. 2007. The green studio handbook: environmental strategies for schematic design. Architectural Press. Oxford. 
[LEAD] Leadership for Environment and Development. 2016. Knowledge hub on sustainable development goals (SDGs) 2015-2030: briefing note. LEAD. Islamabad.

Li XY, Xie ZK and Yan XK. 2003. Run off characteristics of artificial catchment materials for rainwater harvesting in the semiarid regions of China. Agricultural Water Management 65(3):211-224.

Nadia F dan Mardyanto MA. 2016. Perencanaan sistem penampung air hujan sebagai salah satu alternatif sumber air bersih di Rusunawa Penjaringan Sari, Surabaya. Jurnal Teknik ITS 5(2):D241-D246.

Nurrizqi EH, Hadi MP dan Suprayogi S. 2016. Model pemanenan air hujan (rainwater harvesting) untuk mengurangi dampak bencana banjir di DAS Penguluran, Kec. Sumbermanjing Wetan, Kab. Malang [Tesis]. Program Studi S2 Geografi, Universitas Gadjah Mada. Yogyakarta.

PerMenDikNas (Peraturan Menteri Pendidikan Nasional) Nomor 40 Tahun 2008 tentang standar sarana dan prasarana Sekolah Menengah Kejuruan/ Madrasah Aliyah Kejuruan (SMK/MAK).

Rahman S, Khan M, Akib S, Din NBC, Biswas S and Shirazi SM. 2014. Sustainability of rainwater harvesting system in terms of water quality. The Scientific World Journal 2014:1-10. http://dx.doi.org/10.1155/2014/721357.

Smotherman F. 2013. Designing rainwater harvesting systems integrating rainwater into building systems. John Wiley \& Sons, Inc. Ontario.

[SNI] Standar Nasional Indonesia 03-706-2005. 2005. Tata cara perencanaan sistem plambing. Badan Standardisasi Nasional. Jakarta.

Southface Energy Institute. 2002. Rainwater harvesting: energy technical bulletin [internet]. Tersedia di: http://www.southface.org/factsheets/27_ rainwater-recovery-v2.pdf.

[USSCS] USDA Soil Conservation Service. 1973. Drainage of agricultural lands: a practical handbook for the planning, design, construction and maintenance of agricultural drainage systems. USSCS. Washington.

Worm J and Hattum TV. 2006. Rain water harvesting for domestic use, first edition. Digigrafi. Wageningen. 